\title{
Discussion on Electrical Automation Theory and Practice Teaching Mode
}

\author{
Gang Yan \\ JiLin Railway Technology College,China \\ 284756245@163.com
}

Keywords: electrical automation, theory teaching, practice teaching.

\begin{abstract}
Electrical automation is one of the main subjects in industry. With the development of the society, the requirement of electrical automation talent is higher. In order to cultivate more and more high-quality and high skills professional, We think highly of the importance of the good and novel teaching method in both theory, practice, and their combination as well. We also propose a theory and practice integrated steps-like teaching model.
\end{abstract}

\section{Introduction}

Talent training model is a relatively fixed organization framework and operation mode, according to the education goal, education idea, and training objectives, following certain procedures, and using certain methods of educational knowledge, ability and quality training, to achieve the desired training standard ${ }^{[1]}$. How to gain a foothold in 21 st century development of the strategic height to grasp the position of university, advancing with the times to reform the personnel training mode, improving teaching quality and competitiveness, reducing the gap between social needs and the quality of school graduates supply, solving the disjointed problems of theory and practice in teaching, has become an important topic concerned in the colleges and universities.

Electrical engineering and automation is a new subject in the field of electrical information, but because of it is closely related to people's daily life and industrial production, its development is very fast, and it is relatively mature now. It has become an important part of the high-tech industry, widely used in the fields of industry, agriculture, national defense, playing an increasingly important role in the national economy. The professional students can be engaged in system operation about electrical engineering, automatic control, power electronics technology, information processing, testing technology, economic management, and electronic and computer technology applications in etc., is broad caliber "composite" senior engineering and technical personnel. The demand for high level talents in this field is very great. It is estimated that with the entry of large foreign enterprises to our country, there will be a phenomenon of talent shortage in this field. With the increasing demand of electrical automation professionals, electrical automation teaching training should also carry on the corresponding reform and the innovation, strengthen the analysis and research on the practical teaching while teaching theory, in order to cultivate the electrical automation professionals whose theoretical knowledge and practical skills are both excellent.

\section{Electrical automation theory and practice teaching concept}

Electrical automation is one of the courses that need the good combination of theory and practice. Different theoretical courses varies with different professional technology, no matter what kind of professional theory course requires the reasonable curriculum time arrangement. First of all, it needs pertinence, should serve applications, and also want to have strong practicality, pay attention to the combination of theory and practice. Electrical automation theory courses is the basis of professional skills courses, without a well-knit theoretical foundation of it, it is hard to carry out practical courses, even if get good practical skills, it just means that you can only do some operation, it is not good for a person future development. The training course of electrical automation is of great significance to the training of students' practical ability, and it is an important embodiment of high quality talents. The training process of students' skills is a comprehensive training of the ability 
of observation, thinking and imagination ${ }^{[2]}$. It plays a very important role in developing students' thinking ability. Training course is also different from the profession, it is the application process of the theory course in practice. The training goal of electrical automation course is to train the technical personnel of the first line, and it is required to have good theoretical knowledge and practical skills.

\section{Analysis on the theory teaching of electric automation}

Reasonable teaching curriculum arrangement. To achieve good teaching effect, first of all, we must carry out reasonable teaching arrangement. According to the characteristics of the electrical automation professional, making a plan of its teaching curriculum. For the teaching content, should be arranged from easy to difficult, from the basic knowledge to the expanded knowledge, so that students can learn the knowledge step by step. For example, the difficult courses such as relay protection, high voltage technology and so on, should be carried out after the easy and basic courses such as circuit theory, digital electronic technology and so on. Plans like this are reasonable, it can not only improve students' interest, but also improve the efficiency and effectiveness of teaching. Meanwhile, the selection of teaching materials should make sense, following rules are required, firstly, the content of the selected teaching materials must within students' capability. Secondly, teaching materials are required to be easy to understand, advance gradually in due order; 3) materials should be polemical, heuristic and thought-provoking.

Analysis on teaching methods of innovation theory. The traditional teaching method is no longer suitable for the needs of today's teaching, with the continuous deepening of teaching and reforming, some innovative teaching methods are more and more needed to guide today's teaching system.

(1) The teaching method driven by question. As we all known, Many theorems' conditions and conclusions are not knew in advance, but it was obtained by the continuous analysis and research on specific and special phenomenon through scientific thinking method by scientists. Therefore, teaching should stimulate the students' interest in learning and inquiry of passion from the point of view of creating problem situation, and guide the students to active to study and experience the knowledge's changing process, restoring the original thinking. Teachers should try their best to encourage students to think critically and pronouncing independent opinions, so that can improve their creative thinking ability and innovation ability Teachers should be students, but not knowledge. Teachers should inspire students to thinking together through the course of the difficult points and key points. The prerequisite of good interaction is that students' enthusiasm is aroused. In this way, teaching effect will be better presented.

(2)The teaching method with the help of multimedia technology. One of the manifestations of the creative teaching method in the teaching process is the appropriate use of multimedia technology. The use of multimedia technology in the process of classroom teaching can bring the following advantages for teaching quality and teaching effect:1) the teaching content can be showed dynamically, and display the different contents with different color, such can display the direct contact of all the things stereoscopically. 2) Through pictures or data tables, multimedia technology can make a clear performance of the things that is difficult to express in words. 3) Multimedia technology can give a good presentation for the complex content and the whole content, and the students can easily catch the idea just at a glance. 4) Multimedia technology can make classroom interaction easier and build a good atmosphere, so students can better understand and accept the teaching content.

\section{Research on practical teaching in electrical automation}

In order to improve the effect of practical teaching, we adopt flexible practical teaching mode, combining the independent practical courses and the comprehensive design practical courses. First, take the electrical automation practical teaching course as an independent course, make it no longer belongs to the curriculum theory, improve the teaching status of practical courses, and also lay the 
foundation for the quality of the automation experiment. On the one hand, letting the practical course be independent makes it has its own teaching materials and methods. Combining the multi teaching methods with each other can effectively prevent the teaching content repeated and out of touch. On the other hand, it provides comprehensive experiments with a broad space, and makes the practical courses closely related to the production. It is more scientific and advanced. At the same time, it gives much convenience to the update of teaching content, under the policy of teaching reform. It can fundamentally improve the teaching quality of electrical automation practical teaching, laying a solid foundation of cultivating students' practical ability.

Secondly, carry out comprehensive design practical courses. The goal of setting up the practical course is to cultivate students' comprehensive ability, and to realize it by the comprehensive experiment. The complexity and difficulty of comprehensive experiments are much improved, all the single knowledge will be included to get comprehensive training. At this time, students must take consideration of the basic knowledge of electrical and automation theory course. At the same time, we need to train the students to use the comprehensive knowledge to solve the practical electrical automation engineering design problems. Increasing the difficulty of the design in the training process appropriately, so as to cultivate the students' ability of design. Pay more attention to put forward some specific engineering system design index, while setting the training goal, so that the training course is more close to the actual project. It makes the students begin to get in touch with the real engineering practical operation when they are in the experimental room, but not just concentrate on the system function achievement. Therefore, the design of the practical course content seems to be particularly important.

\section{Theory and practical integrated steps-like teaching mode}

According to the demand of practical personnel, practice teaching can be divided into routine practice teaching and high level practice teaching. Practice teaching is classified no matter by whether by function, the integration of the content, the form of organization, the students' role in the teaching practice, or the classification of activity places, all kinds of experiments are reflected in form of experimental courses or independent experiment course in talent culture scheme ${ }^{\text {[3] }}$. Through the analysis of the current social demand for electrical automation talent and colleges' experimental courses system, a theory and practical integrated steps-like teaching mode is proposed.

(1)Extending theory teaching by routine practice. Routine practice teaching includes case teaching, course experiment, and centralized practical. Routine centralized practice teaching links in general compromised by cognitive practice or social survey, curriculum design or academic papers, professional practice ${ }^{[4]}$. Integrate the theoretical teaching and practical teaching in teaching organization. In class, achieve the docking of theory teaching and practice by case driven and interactive teaching. Taking advantage of experiments to integrate theory and practice in theory course. Through cognitive internship and social investigation, curriculum design or academic papers, professional practice conventional centralized practice to achieve teaching theory extension.

(2)High level practice teaching. High level of practice includes: independent experimental course, the domestic and overseas internship program, the second classroom innovation practice, employment oriented practice (professional practice, entrepreneurial practice), graduation practice and graduation thesis ${ }^{[5]}$. Independent experimental curriculum are set in personnel training scheme to enrich and deepen the theoretical teaching. Set up domestic and overseas project to seamlessly connected teaching to industry demand. Set up entrepreneurial practice teaching to docking with the frontier market. Integrating with high-end industry by innovative practice. Finally, form a theory and practical integrated steps-like teaching mode, which is dominated by experiment in school, supplemented by practice outside school, and regard theory teaching and practical teaching as equally important. In recent years, all kinds of colleges and universities have become more and more attention to the development of the experimental teaching of electrical automation, but the understanding and the specific setting of high-level practice is not clear enough. The traditional practice teaching is defined as the extension of the theory teaching, which belongs to the theoretical teaching ${ }^{[6]}$. The training goal of electrical automation specialty is to cultivate excellent talents who 
have the profound theoretical foundation, and can combine theory and practice. High level practice is major to develop the sustainable development ability of and the innovative practice ability of talent practical personnel, and it integrates theory and practice closely. By setting up the high level practice to achieve the sublimation of theoretical teaching, cultivate electrical automation talent who has high theoretical quality, and good practical ability.

\section{The organic connection between teaching and market demand}

Teaching and the market demand is complementary, good teaching quality will bring more talents, so as to promote the high-speed development of society. Market demand of high-quality, high skills and innovative talents promotes the reform and development of colleges and universities teaching method. Entrepreneurship for college graduates is not only an important way for the employment, but also an external form of social responsibility. College education should encourage and guide students go to start a new path to docking with the forefront of the market, and organic docking. Entrepreneurial practice teaching takes business practices on campus curriculum as the main body, through the entrepreneurial practice teaching software platform and the entrepreneurial practice network simulation environment, to carry out the teaching of entrepreneurship practice, specify and clear entrepreneurial practical way, the content, the process and the risk. To enhance the students' awareness of entrepreneurship practice through a business plan competition, leading entrepreneurial practice. In addition, trying to set up a pioneering park and the campus business incubators or center, introducing the risk fund, providing business platform, offering an external business environment to business students.

Innovative practice is the high-end extension of theory teaching, is the senior goal of training practical personnel. Its main content is to closely integrate specific theoretical knowledge and innovation practice, and achieve the mutually communication of innovation practice and high-end industry. The innovative practice teaching mainly includes the following contents. Carry out the student research training and innovation experimental program, advocate student-centered research learning and innovative experimental activities. Establish fund for student innovation practical project, take the students' interests as the starting point. Focus on funding a group of college students' research-study and innovative experiment project, aiming at cultivate practical personnel who has good innovation ability, by the way of stimulating the creative thinking and consciousness.

\section{Summary}

Aiming to solving the problem of the disjoint of electrical automation theory teaching and practical teaching, we take a research on their effective combination. Electrical automation is a subject which has strong practical applicability, theory teaching and practical teaching are equally important for it. In the teaching process, we should adopt novel and various theory teaching and practical teaching method, make more extension and closely integrate them. The theory teaching is the foundation, while the practical teaching is the building on it. There will not be a good building without either of them.

\section{References}

[1] Zhao G. The research and practice for new model of teaching on Electrical Engineering and automation subject based on "Design, Practice and Ability"[C]// Educational and Information Technology (ICEIT), 2010 International Conference on. IEEE, 2010:V3-68-V3-70.

[2] Xue-Jun L I, Jie L I, Ming-Jing L I. Discussion on the Reform of the Practice Teaching in the Major of Electrical Engineering and Automation. Journal of Changchun University, 2013.

[3] Zhao L. Hydro Practice Teaching System Exploration on Electrical Engineering and Automation Specialty. Guide of Science \& Education, 2014. 
[4] Wei L M, Han C H, Chen W L. Research on Teaching Reform of Motor and Drag of Electrical Engineering and Automation Specialty in Architectural Institute. China Construction Education, 2011, 1375(2):103-110.

[5] Han K, Hao J. Discussion on practice teaching section for excellent engineers education training of electrical engineering and automation. China Modern Educational Equipment, 2014.

[6] Wei L M, Han C H, Wang C Z. Comprehensive Teaching Reform of Electrical Engineering and Automation Professional Applied Talents. Journal of Jilin Institute of Architecture \& Civil Engineering, 2013. 